\title{
Functional Anatomy and Histology of the Olfactory Organ in Korean Eel Goby, Odontamblyopus lacepedii (Pisces: Gobiidae)
}

*Correspondence to:

Park JY,

(iD) http://orcid.org/0000-0003-2348-5111

Tel: +82-63-270-3344

Fax: +82-63-270-3362

E-mail: park7877@jbnu.ac.kr

Received February 2, 2018

Revised March 12, 2018

Accepted March 18, 2018

\author{
Hyun Tae Kim, Yong Joo Lee ${ }^{1}$, Jong Young Park* \\ Faculty of Biological Science and Institute for Biodiversity, College of Natural Science, \\ Chonbuk National University, Jeonju 54896, Korea
${ }^{1}$ Jeonju National University of Education, Jeonju 55101, Korea \\ Chonbuk National University, Jeonju 54896, Korea
1 Jeonju National University of Education, Jeonju 55101, Korea
}

For Odontamblyopus lacepedii with small and turbid eyes, the gross structure and histology of the olfactory organ, which is important for its survival and protection of the receptor neuron in estuarial environment and its ecological habit, was investigated using a stereo, light and scanning electron microscopes. Externally, the paired olfactory organs with two nostrils are located identically on each side of the snout. These nostrils are positioned at the anterior tip of the upper lip (anterior nostril) and just below eyes covered with the epidermis (posterior nostril). Internally, this is built of an elongated olfactory chamber and two accessory nasal sacs. In histology, the olfactory chamber is elliptical in shape, and lined by the sensory epithelium and the non-sensory epithelium. The sensory epithelium of a pseudostratified layer consists of olfactory receptor neurons, supporting cells, basal cells and lymphatic cells. The non-sensory epithelium of a stratified layer has swollen stratified epithelial cells and mucous cells with acidic and neutral sulfomucin. From these results, we confirmed the olfactory organ of O. lacepedii is adapted to its ecological habit as well as its habitat with burrows at the muddy field with standing and murky waters.

Key Words: Odontamblyopus lacepedii, Olfactory organ, Anterior nostril, Two nasal sac, Mucous cell

\section{INTRODUCTION}

Odontamblyopus, a genus of eel gobies which live in intertidal zone or coastal estuaries, has currently 5 species in the world, being distributed in Taiwan, Southern China, Japan and Korea (Murdy \& Shibukawa, 2001). Among them, Odontamblyopus lacepedii has been known as an ambush predator or sit-and wait-predator, and except for the dorsal part of its head, the rest commonly are at burrows (Kim, 1997). With small and turbid eyes, such behavioral movement may let the feeding method use gustation and olfaction. Indeed, their habitats are very unstable because the muddy bottom may heavily be affected by periodic tidal cycles and coastal waves (Kim et al., 2005). In such drastic environmental events, their feeding activity is likely to have no choice but to rely on olfaction rather than vision. In so many teleost fishes, the perception of mobile organisms is conducted by two major receptions, vision and olfaction (Guthrie, 1986; Hara, 1986). In particular, fishes having degenerative and blind eyes have been an object of interest in aspect of the mechanism for their chemoreception (Baker \& Montgomery, 1999; Sarma et al., 2003). For O. lacepedii, the olfactory organ may be important for its survival and protection of olfactory receptor neurons (ORNs) against fine muddy particles and harmful substances in the estuarial environment. As part of elucidating the relation between the organ and chemoreception, therefore, a gross anatomical structure, histological and histochemical characteristics on the olfactory organ is studied by a stereo

@ This is an open-access article distributed under the terms of the Creative Commons Attribution Non-Commercial License (http://creativecommons.org/licenses/by-nc/4.0) which permits unrestricted noncommercial use, distribution, and reproduction in any medium, provided the original work is properly cited.

Copyrights (C) 2018 by Korean Society of Microscopy 
microscopy (SM), light microscopy and scanning electron microscopy.

\section{MATERIALS AND METHODS}

During the low tides from March to April, O. lacepedii (Fig. 1A) ( $\mathrm{n}=30$ in $260.5 \sim 350.6 \mathrm{~mm}$ in standard length), were caught by a fisherman in an estuarial shore of Jangamri, Beolgyo-eup, Boseong-gun, Jeollanam-do, South Korea, $34^{\circ} 48^{\prime} 25^{\prime \prime} \mathrm{N}, 127^{\circ} 24^{\prime} 59^{\prime \prime} \mathrm{E}$ (Fig. 1B). After collected by a fixed net, ten specimens were anesthetized with
$0.1 \% \mathrm{~m}$-aminobenzoic acid ethylester methanesulfonate (MS222; Sigma, USA) immediately in the field. Then each three among them were fixed with $10 \%$ neutral buffered formalin and $2.5 \%$ glutaraldehyde solution with $0.1 \mathrm{M}$ phosphate buffer, respectively. The remainder was used for anatomical observation of the olfactory organ. For more defined structure, the olfactory parts of the specimens fixed with $10 \%$ formalin solution were dyed with hematoxylin stock solution. While being dissected from the head under a SM (Stemi DV4; Carl Zeiss, Germany), the olfactory organ was observed and filmed with a digital camera (TG-
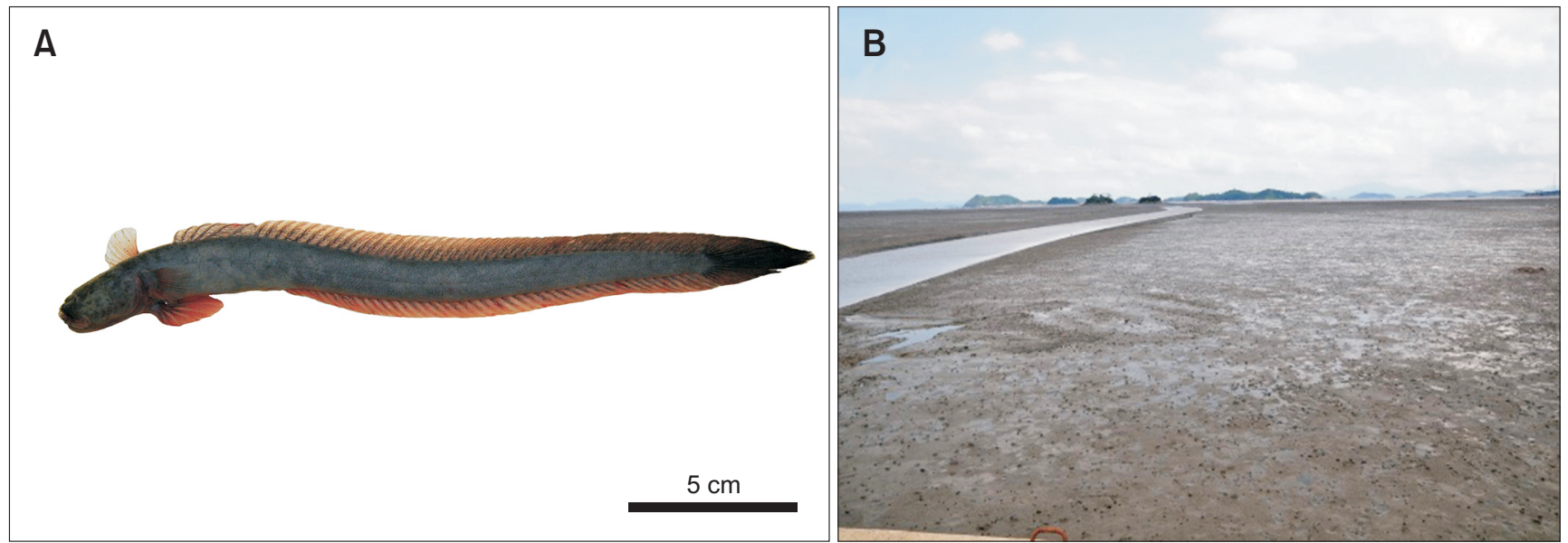

Fig. 1. The photographs (A) and habitat (B; estuarial environment at the low tide) of Odontamblyopus lacepedii.
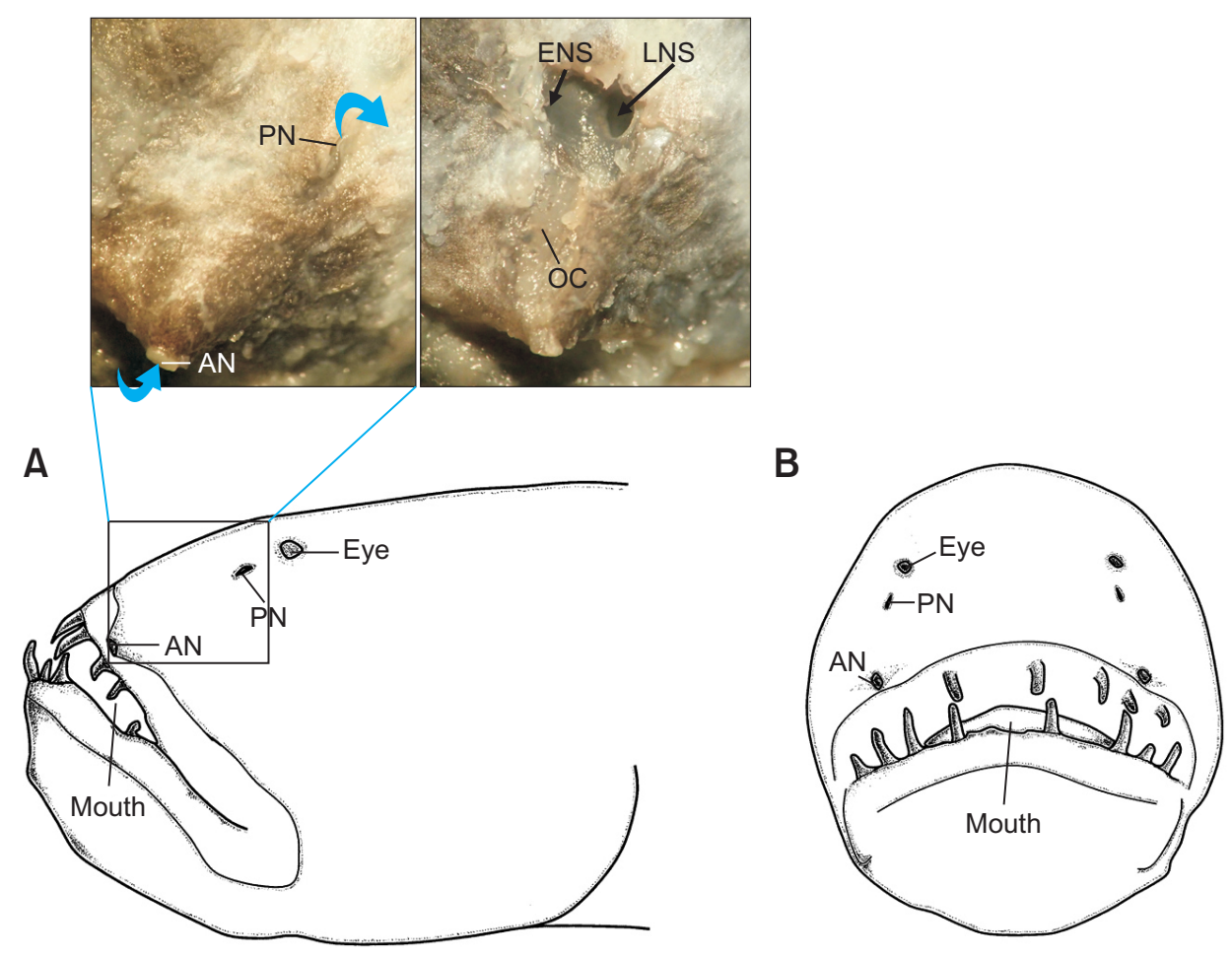

Fig. 2. Schematic diagrams of the side (A) and front (B) views in the head of Odontamblyopus lacepedii. The above photographs show external (left) and internal (right) structures of the olfactory organ and bent blue arrows indicate a water flow. AN, anterior nostril; PN, posterior nostril; ENS, ethmoidal nasal sac; LNS, lacrymal nasal sac; OC, olfactory chamber. 
3; Olympus, Japan). For histology, the fixed olfactory tissues were dissected out from the head. They were dehydrated with ascending series of ethanol, cleaned with xylene, and then were embedded into paraffin wax blocks (Paraplast; Oxford, USA) for 24 hours. Five-micrometer sections with the olfactory fragments were cut in a microtome (Leica 820; Leica, Germany), deparaffinized, stained with Harris's H\&E (Gurr, 1956) and Masson trichrome (Masson, 1929) for a general histology. To recognize the nature of mucous cells (MCs), several special staining techniques were employed: (1) periodic acid Schiff (PAS) and diastase/PAS for the detection of 1,2 glycol group and (2) hematoxylin, Weigert iron and toluidine blue for the amino group and (3) alcian blue (AB) $\mathrm{pH} 1.0$ and $\mathrm{pH} 2.5$ for both carboxyl group and sulfate group and (4) mild methylation, methylation-saponification and aldehyde fuchsin- $\mathrm{AB}$ for the identification of the sulfated-and carboxylated mucosubstances, and (5) few double stains.

\section{RESULTS}

\section{Anatomy}

The paired olfactory organs of O. lacepedii are situated at the dorsal part of the snout in the head, and have two nostrils per one organ (Fig. 2). These nostrils arranged at an interval distance of 4.76 to $6.02 \mathrm{~mm}$ are largely subdivided into the anterior and the posterior nostrils. The anterior nostril (0.29 0.73 $\mathrm{mm}$ in diameter) has an open tube-like shape, and is at the anterior tip (forward direction) of the snout. The posterior one at front of the eyes is a slit close to the exterior. The internal structure consists of an elongated olfactory chamber and two accessory nasal sacs (ethmoidal and lacrymal sacs) being expanded proximally. A folded lamella was not observable in the olfactory chamber (Fig. 2; the photograph inserted).

\section{Histology}

In histology, the inner floor of the olfactory chamber is lined by two distinct regions of the epithelium: the sensory epithelium (SE) and the non-sensory epithelium (NSE) (Fig. $3 \mathrm{~A})$. The $\mathrm{SE}$ is a pseudostratified layer, which has the ORNs, supporting cells (SCs), basal cells (BCs), and lymphatic cells (LCs), and occurs in the lateral and ventral parts of the olfactory chamber (Fig. 3B and C). With a dendrite and exon, the ORNs are an elongated bipolar cell extending from the basement membrane to the superficial surface layer of the epithelium. These neurons have a nucleus with numerous nucleoli and deep reddish purple positive for hematoxylin and dark reddish violet stained by Weigert iron hematoxylin. The SCs are a cylindrical cell with a large and oval nucleus at the superficial layer of the epithelium and they are stained more weakly by hematoxylin and Weigert iron hematoxylin. Without an extending process, they have cilia at the apical surface of the cell body. The BCs are a rounded cell without any processes and they are situated just above the basement membrane. Their nucleus has vertical and horizontal position and contains many nucleoli with a purple color stained by hematoxylin and Weigert iron hematoxylin. Their cytoplasm is very little. The LCs are almost a circular cell existing in both the epithelium and the connective tissue. With an extremely little cytoplasm, they have a deeply dark color stained by hematoxylin and Weigert iron hematoxylin.

The connective tissue has well-developed blood capillaries occurring abundantly just below the basement membrane (Fig. 3B and C). The blood capillary has 3 to 10 units of oval
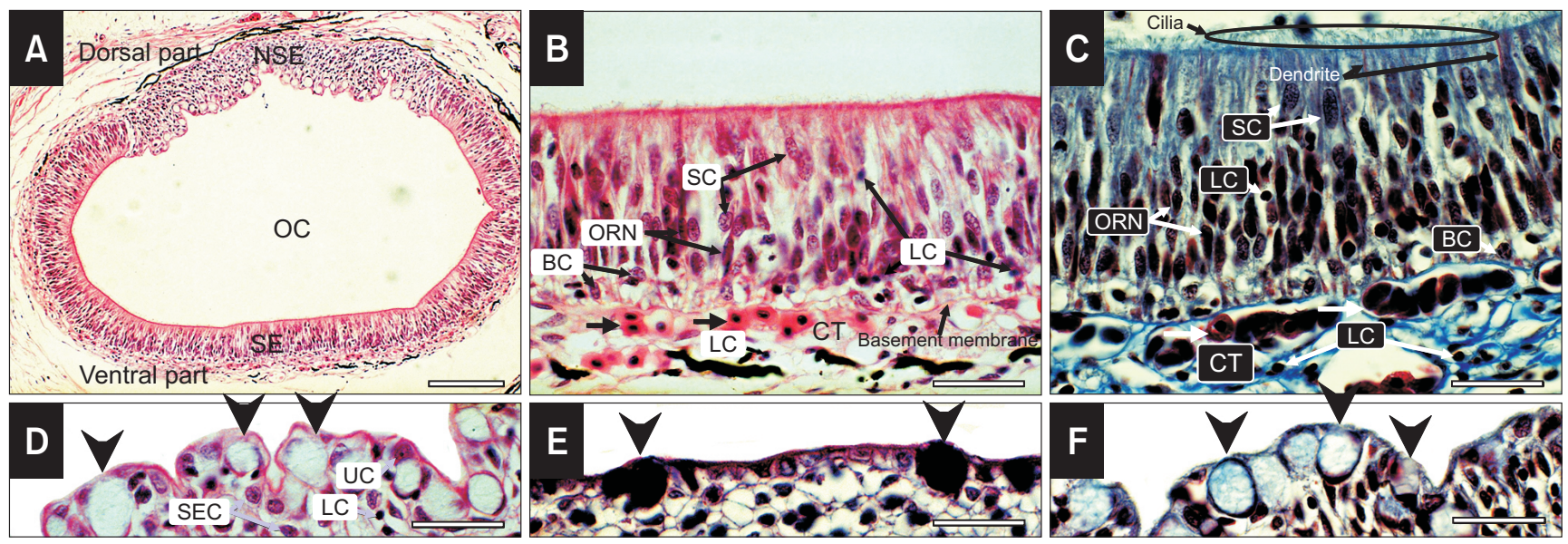

Fig. 3. Histological characteristics of the olfactory epithelium and cells in Odontamblyopus lacepedii with H\&E (A, B, D), Masson's trichrom (C, F) and Alcian blue (pH 2.5)-periodic acid Schiff (E). (A) The olfactory chamber (OC) divided into the sensory epithelium (SE) and non-sensory epithelium (NSE). (B, C) The SE organized by the olfactory receptor neurons (ORNs), the supporting cells (SCs), the basal cells (BCs), and the lymphatic cells (LCs). CT, connective tissue. (D) The NSE consisting of the stratified epithelial cells (SECs), the LCs, the mucous cells (MCs) and the unidentified cell (UC). (E) MCs with reddish black color. (F) MCs with bluish color. Black and white arrows, blood capillaries; arrowheads, MCs. Scale bars=200 $\mu \mathrm{m}$ (A), $50 \mu \mathrm{m}$ (B-F). 

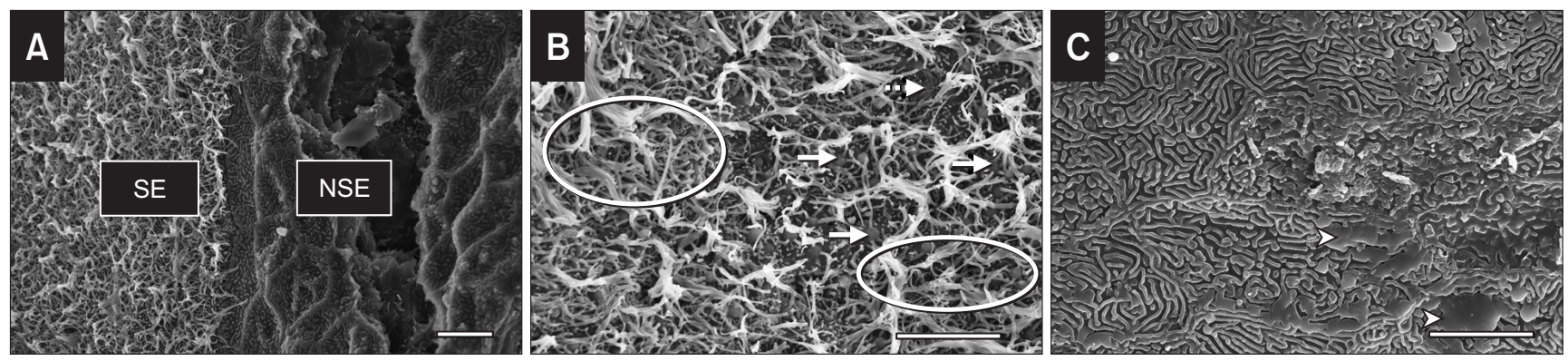

Fig. 4. Scanning electron micrographs showing the surface of the olfactory epithelium. (A) The olfactory epithelium subdivided into the sensory epithelium (SE) and the non-sensory epithelium (NSE). (B) The SE showing cilia bundles, ciliated and microvillous olfactory receptor neurons (ORNs). (C) The NSE showing a labyrinth form and mucous mass. Large ellipses, cilia bundle; dotted arrow, microvillous ORNs; solid arrow, ciliated ORNs; arrowheads, mucous mass. (A-C) Scale bars $=5 \mu \mathrm{m}$.

blood cells.

The NSE is a stratified squamous layer and they have stratified epithelial cells (SEC), LCs, MCs, and unidentified cells (UCs) (Fig. 3D-F). The SECs are a basic cell organizing the NSE, and they have an oval or somewhat flattened nucleus with numerous nucleoli. Also, they are distributed from the bottom to the superficial layer of the epithelium and there is a swollen cytoplasm with a faint color, not to be stained by hematoxylin and eosin, Masson's trichrome. The LCs are scattered randomly between contents of the epithelial layer, and they are similar to the SE in morphology and dyeing. The MCs are a large and rounded cell with cytoplasmic contents showing variable colors (faint color in hematoxylin and eosin, reddish black in $\mathrm{AB}$ [ $\mathrm{pH}$ 2.5]-PAS, weakly bluish color in Masson's trichrome). Their flattened nuclei are situated at the bottom of the cell body, being stained by hematoxylin and Weigert iron hematoxylin. The UCs occur in the superficial surface layer, and they are arranged at the side of MCs. They have a little cytoplasm stained strongly by eosin.

In the SEM, the surface of the olfactory epithelium is divided into the SE and the NSE (Fig. 4), being distinguished by the presence or absence of the long cilia (Fig. 4A). In the SE, the cilia from the SCs are tangled and twisted for each other, and are different from relatively short cilia of the ciliated ORNs. With 4 to 5 units of cilia projecting from the olfactory knob, the ciliated ORNs are randomly visible on the surface of the SE. With 9 to 15 units of tiny microvilli, the microvillous ORNs occur between the ciliated ORNs and the SCs (Fig. 4B). Overall, the distributional pattern of the SE shows a continuous type. The NSE forms labyrinth to make creases like fingerprints on the surface, and has a mucous mass agglomerated in variable size (Fig. 4C).

\section{Histochemistry}

The MCs involves acidic and neutral mucus with showing a red color in PAS, a blue color in $\mathrm{AB}(\mathrm{pH} 1.0)$ and a reddish black in $\mathrm{AB}$ ( $\mathrm{pH}$ 2.5)-PAS. In a sort of carboxylate, these cells
Table 1. The characteristics of the mucous cell by employed techniques

\begin{tabular}{lc}
\hline \multicolumn{1}{c}{ Characteristic } & Employed techniques \\
\hline H\&E & - \\
Weigerts iron & - \\
Hematoxylin & - \\
Masson trichrome & Blue \\
PAS & Red \\
PAS after digestion in malt diastase/PAS & Red \\
Alcian blue (pH 1.0) with NFR & Blue \\
Alcian blue (pH 2.5) with NFR & - \\
Alcian blue/PAS & Reddish black \\
Toluidine blue O & $\beta$-meta \\
Methylation/saponification/AB & - \\
Mild methylation/AB & Blue \\
Aldehyde fuchsin/AB & Purple \\
\hline
\end{tabular}

PAS, periodic acid Schiff; NFR, nuclear fast red; -, negative; $\beta$-meta, $\beta$-metachromasia.

show a metachromatic sulfomucin by a purple color positive for aldehyde fuchsin/AB, a blue color by mild methylation/ $\mathrm{AB}$, and Toluidine blue $\mathrm{O}$ (Table 1).

\section{DISCUSSION}

With a nose and blind eyes, O. lacepedii hides within underground burrows of mud-bottomed estuaries during waiting for prey at ordinary time (Murdy \& Shibukawa, 2001). At that time, therefore, the water ventilation in $O$. lacepedii is only possible by the olfactory organ. Because the head structure of fish is affected directly by aquatic environment and ecological habits, the olfactory organ may be related to the skeletal structure and position of the head (Whiteley, 2007). As in other teleost fishes, O. lacepedii also has basic olfactory contents such as the olfactory chamber and two nostrils at the dorsal snout of the head (Kasumyan, 2004). Nevertheless, this eel goby has somewhat different structures in its morphology as following: (1) a forward and tubular 
anterior nostril situated at the anterior tip of the upper lip, (2) a slit posterior nostril, (3) an elongated canal-like chamber, and (4) two accessory nasal sacs. Such structures may be considered a significant architecture to help an intentional water ventilation by two accessory nasal sacs. It has been known in bottom-dwelling fishes like gobiid fishes that are inactive species living in the stagnant water system (Kuciel et al., 2013; Zeiske et al., 1992). In particular, two accessory nasal sacs, which ventilate the water through a volume alteration by release and contraction, may be essential for O. lacepedii who lives in the shallow and standing water with murky quality at the low tide (Doving, 1986). Even the anterior nostril with the forward direction at the anterior tip of the snout seems to be a unique character which is not reported in other gobiid fishes so far. Such a unique position of the anterior nostril may be closely related to its ecological habit that its nose and eyes are exposed out of the burrow.

The olfactory epithelium of $O$. lacepedii consists of the SE and the NSE, like other gobiid fishes showing variable epithelial distributions by species (Kuciel et al., 2013). They are also known as an amphibious fish to survive on land out of water (Park et al., 2003), called an air- breather fish. Among air breathing fishes, the distributional pattern of SE of Boleophthalmus boddarti, Scartelaos histophorus, and O. rubicundus (the congener of O. lacepedii) shows a continuous type as identified in this study (Yamamoto, 1982), whereas Periophthalmus barbarus, Periophthalmus variabilis, Periophthalmus chrysospilos have an islet type. In general, the genus Periophthalmus is better able to tolerate the aerial exposure during the low tide than genera Odontamblyopus, Boleophthalmus and Scartelaos (Chew \& Ip, 1992; Tamura et al., 1976; Tytler \& Vaughan, 1983).

The stratified squamous layer of the NSE of O. lacepedii includes polygonal cells from the basal part to the surface layer, In the cross section, this layer shows interestingly an indented outermost surface, unlike a flattened surface seen in many teleost fishes (Chakrabarti \& Ghosh, 2010;
Ghosh \& Chakrabarti, 2009; Mandal et al., 2005), including some gobiid fishes such as P. barbarus and Pseudapocryptes lanceolatus (Kuciel et al., 2011; Sarkar \& De, 2011). Although the exact reason for forming this structure is not known, it is evident that such a folded surface seems likely to increase its secretory area because the outermost superficial layer of the NSE in O. lacepedii has abundant MCs. The MC is a unicellular merocrine gland, and they are acidic and neutral sulfomucin, proved by $\mathrm{PAS}, \mathrm{AB}(\mathrm{pH}$ 2.5)-PAS, mild methylation/ $\mathrm{AB}$ and aldehyde fuchsin/ $\mathrm{AB}$ stains. This material has also been reported in diverse organs, such as spermatic duct (Lahnsteiner \& Patzner, 1990), skin (Zuchelkowski et al., 1985), gut (Venkatesh et al., 2014), liver (Bagale et al., 2015), and in addition olfactory organ (Doroshenko, 2007). This cell (sometimes goblet cell) (Verdugo, 1990), may be important in the multi-cell layer for protecting ORNs and other olfactory cells from any hazardous factors surrounding the environment (Shephard, 1994).

\section{CONCLUSIONS}

In anatomy, the paired olfactory organ in O. lacepedii has an anterior nostril with a tubular structure at the anterior tip of the upper lip and a slit posterior nostril, ethmoidal and lacrymal accessory nasal sacs. They have the SE (a continuous pattern), folded NSE, olfactory cells, LCs, and MCs with acidic and neutral sulfomucin. This species, the green eel goby, lives in burrows dug up on the muddy field with standing and murky waters in the estuary and the coastal region. Consequently, such structures on the olfactory organ may be related to its behavioral habitat and ecological habit, as part of conducting the perception to the environmental change.

\section{CONFLICT OF INTEREST}

No potential conflict of interest relevant to this article was reported.

\section{REFERENCES}

Bagale M B, Rao K R, Kshirsagar S S, and Shah N V (2015) Sodium fluoride induced histochemical changes in the liver of freshwater fish, Tilapia mossambica (Oreochromis mossambicus). Bioscan 9, 10891092.

Baker C F and Montgomery J C (1999) The sensory basis of rheotaxis in the blind Mexican cave fish, Astyanax fasciatus. J. Comp. Physiol. 184, 519-527.

Chakrabarti P and Ghosh S K (2010) Histological and scanning electron microscopical study of the olfactory epithelium of the Indian major carp, Catla catla (Hamilton). Folia Morphol. 69, 24-29.

Chew S F and Ip Y K (1992) Biochemical adaptations of the mudskipper
Boleophthalmus boddaerti to a lack of oxygen. Mar. Biol. 112, 567 571.

Doroshenko M A (2007) Glands in the olfactory epithelium of marine fish. J. Ichthyol. 47, 449-455.

Doving K B (1986) Functional properties of the fish olfactory system. In: Progress in Sensory Physiology, ed. Ottoson D, pp. 39-104, (Springer, Berlin).

Ghosh S K and Chakrabarti P (2009) Cellular architecture and functional aspects of the olfactory rosette of Wallago attu (Bleeker). Turk. J. Fish Aquat. Sci. 9, 187-190. 
Gurr G T (1956) A Practical Manual of Medical and Biological Staining Techniques, pp. 1-99, (Interscience, New York).

Guthrie D M (1986) Role of vision in fish behaviour. In: The Behaviour of Teleost Fishes, ed. Pitcher T J, pp. 75-113, (Springer, Boston).

Hara T J (1986) Role of olfaction in fish behaviour. In: The Behaviour of Teleost Fishes, ed. Pitcher T J, pp. 152-176, (Springer, Boston).

Kasumyan A O (2004) The olfactory system in fish: structure, function, and role in behavior. J. Ichthyol. 44, 180-223.

Kim I S (1997) Illustrated Encyclopedia of Fauna and Flora of Korea. Freshwater Fishes, pp. 483-484, (Ministry of Education, Seoul). Korean.

Kim I S, Choi Y, Lee C L, Lee Y J, Kim B J, and Kim J H (2005) Illustrated Book of Korean Fishes, 615 pp., (Kyohak Publishing, Seoul). Korean.

Kuciel M, Żuwała K, and Jakubowski M (2011) A new type of fish olfactory organ structure in Periophthalmus barbarus (Oxudercinae). Acta Zool. 92, 276-280.

Kuciel M, Zuwala K, and Satapoomin U (2013) Comparative morphology (SEM) of the peripheral olfactory organ in the Oxudercinae subfamily (Gobiidae, Perciformes). Zool. Anz. 252, 424-430.

Lahnsteiner F and Patzner R A (1990) The spermatic duct of blenniid fish (Teleostei, Blenniidae): fine structure, histochemistry and function. Zoomorphology 110, 63-73.

Mandal D K, Roy D, and Ghosh L (2005) Structural organization of the olfactory epithelium of a spotted snakehead fish, Channa punctatus. Acta Ichthyol. Piscat. 35, 45-50.

Masson P (1929) Some histological methods: trichrome stainings and their preliminary technique. J. Tech. Methods 12, 75-90.

Murdy E O and Shibukawa K (2001) A revision of the gobiid fish genus Odontamblyopus (Gobiidae: Amblyopinae). Ichthyol. Res. 48, 31-43.

Park J Y, Lee Y J, Kim I S, and Kim S Y (2003) Morphological and Cytochemical study on the skin of Korean eel goby, Odontamblyopus lacepedii (Pisces, Gobiidae). Korean J. Biol. Sci. 7, 43-47.
Sarkar S K and De S K (2011) Functional morphoanatomy of olfactory sensory epithelial cells of Pseudapocryptes lanceolatus (Bloch and Schneider). Int. J. Sci. Nat. 2, 1-6.

Sarma S S S, López-Rómulo J A, and Nandini S (2003) Larval feeding behaviour of blind fish Astyanax fasciatus (Characidae), black tetra Gymnocorymbus ternetzi (Characidae) and angel fish Pterophyllum scalare (Cichlidae) fed zooplankton. Hydrobiologia 510, 207-216.

Shephard K L (1994) Functions for fish mucus. Rev. Fish Biol. Fish. 4, 401-429.

Tamura S O, Morii H, and Yuzuriha M (1976) Respiration of the amphibious fishes Periophthalmus cantonensis and Boleophthalmus chinensis in water and on land. J. Exper. Biol. 65, 97-107.

Tytler P and Vaughan T (1983) Thermal ecology of the mudskippers, Periophthalmus koelreuteri (Pallas) and Boleophthalmus boddarti (Pallas) of Kuwait Bay. J. Fish Biol. 23, 327-337.

Venkatesh P, Jeyapriya S P, Suresh N, and Vivekananthan T (2014) Light microscopic studies on the gut of freshwater fish Channa punctatus (Bloch). Int. J. Rec. Sci. Res. 5, 468-471.

Verdugo P (1990) Goblet cells secretion and mucogenesis. Annu. Rev. Physiol. 52, 157-176.

Whiteley A R (2007) Trophic polymorphism in a riverine fish: morphological, dietary, and genetic analysis of mountain whitefish. Biol. J. Linn. Soc. 92, 253-267.

Yamamoto M (1982) Comparative morphology of the peripheral olfactory organs in teleosts. In: Chemoreception in Fishes, ed. Hara T J, pp. 39-59, (Elsevier, Amsterdam).

Zeiske E, Theisen B, and Breucker H (1992) Structure, development, and evolutionary aspects of the peripheral olfactory system. In: Fish Chemoreception, ed. Hara T J, pp. 13-39, (Springer, Amsterdam).

Zuchelkowski E M, Pinkstaff C A, and Hinton D E (1985) Mucosubstance histochemistry in control and acid-stressed epidermis of brown bullhead catfish, Ictalurus nebulosus (LeSueur). Anat. Rec. 212, 327-335. 